\title{
Article \\ Microstructure Evaluation and Impurities in La Containing Silicon Oxynitrides
}

\author{
Abbas Saeed Hakeem ${ }^{1}\left(\right.$, Sharafat Ali ${ }^{2, *}{ }^{\circledR}$, Thomas Höche ${ }^{3,4}$, Qasem Ahmed Drmosh ${ }^{1}\left(\right.$, Amir Azam Khan ${ }^{5}$ \\ and Bo Jonson ${ }^{2}$
}

Citation: Hakeem, A.S.; Ali, S.;

Höche, T.; Drmosh, Q.A.; Khan, A.A.;

Jonson, B. Microstructure Evaluation and Impurities in La Containing Silicon Oxynitrides. Nanomaterials 2021, 11, 1896. https://doi.org/ 10.3390/nano11081896

Academic Editor:

Akinobu Yamaguchi

Received: 17 June 2021

Accepted: 19 July 2021

Published: 23 July 2021

Publisher's Note: MDPI stays neutral with regard to jurisdictional claims in published maps and institutional affiliations.

Copyright: (C) 2021 by the authors. Licensee MDPI, Basel, Switzerland. This article is an open access article distributed under the terms and conditions of the Creative Commons Attribution (CC BY) license (https:// creativecommons.org/licenses/by/ $4.0 /)$.
1 Interdisciplinary Research Center for Hydrogen \& Energy Storage (IRC-HES) Research Institute, King Fahd University of Petroleum \& Minerals, Dhahran 31261, Saudi Arabia; ashakeem@kfupm.edu.sa (A.S.H.); drmosh@kfupm.edu.sa (Q.A.D.)

2 Department of Built Environment and Energy Technology, Linnæus University, SE-351 95 Växjö, Sweden; bo.jonson@lnu.se

3 Leibniz Institute of Surface Engineering IOM, Permoserstr. 15, D-04318 Leipzig, Germany; thomas.hoeche@imws.fraunhofer.de

4 Fraunhofer Institute for Microstructure of Materials and Systems IMWS, Walter-Huelse-Strasse 1, D-06120 Halle, Germany

5 School of Chemical and Materials Engineering, National University of Science \& Technology, Islamabad H-12, Pakistan; amirazamkhan@msn.com

* Correspondence: sharafat.ali@lnu.se

\begin{abstract}
Oxynitride glasses are not yet commercialised primarily due to the impurities present in the network of these glasses. In this work, we investigated the microstructure and instinctive defects in nitrogen rich $\mathrm{La}-\mathrm{Si}-\mathrm{O}-\mathrm{N}$ glasses. Glasses were prepared by heating a powder mixture of pure La metal, $\mathrm{Si}_{3} \mathrm{~N}_{4}$, and $\mathrm{SiO}_{2}$ in a nitrogen atmosphere at $1650-1800^{\circ} \mathrm{C}$. The microstructure and impurities in the glasses were examined by optical microscopy, scanning electron microscopy, atomic force microscopy, and transmission electron microscopy in conjunction with electron energy-loss spectroscopy. Analyses showed that the glasses contain a small amount of spherical metal silicide particles, mostly amorphous or poorly crystalline, and having sizes typically ranging from $1 \mu \mathrm{m}$ and less. The amount of silicide was estimated to be less than 2 vol. \%. There was no systematic relation between silicide formation and glass composition or preparation temperature. The microstructure examination revealed that the opacity of these nitrogen rich glasses is due to the elemental Si arise from the decomposition reaction of silicon nitride and silicon oxide, at a high temperature above $\sim 1600{ }^{\circ} \mathrm{C}$ and from the metallic silicide particles formed by the reduction of silicon oxide and silicon nitride at an early stage of reaction to form a silicide intermetallic with the La metal.
\end{abstract}

Keywords: oxynitride glass; nitrogen enrich; transparency; defects; electron microscopy; characterisation

\section{Introduction}

Silicon-based oxynitride glasses have become a well-established technological process in glass science and technology since their introduction in the late 1960s. Studies have shown that nitrogen incorporation induces significant structural rearrangements within the glass network, leading to superior thermal, mechanical, optical, and chemical properties. The structural role of nitrogen in the silicate glass network is similar to oxygen, except that some of the nitrogen is linked with three silicon tetrahedra. Most of the potential applications have not been commercialised yet primarily because of the challenges remaining with scaling up the process to mass production and developing a more cost-efficient synthesis method. Another significant challenge is still the production of optically transparent glasses in the visible region. In this paper, we report on the possible reason for the non-transparency of these glasses.

The synthesis of metal containing SiON and SiAlON glasses involve the reaction of solid $\mathrm{Si}_{3} \mathrm{~N}_{4}, \mathrm{SiO}_{2},\left(\mathrm{AlN} / \mathrm{Al}_{2} \mathrm{O}_{3}\right)$, and metal oxides, yielding glasses with nitrogen contents 
up to typically $\sim 30 \mathrm{e} / \mathrm{o}$, or by reacting $\mathrm{NH}_{3}$ or $\mathrm{N}_{2}$ with molten oxides, yielding glasses with nitrogen content less than $10 \mathrm{e} / \mathrm{o}$. Studies have shown that using metal or metal hydride as starting materials, glasses can be synthesised in the $\mathrm{M}-\mathrm{Si}-\mathrm{O}-\mathrm{N}$ (where $\mathrm{M}$ is metal) systems [1-10]. By employing a pure metal or metal hydride, glasses can be obtained with broad compositional ranges retaining high amounts of nitrogen and modifiers.

As compared to oxide glasses, oxynitride glasses are translucent in the visible range. Often these glasses have a grey to black appearance, depending on the concentration of nitrogen and modifier in the silicate glass network. The intensity of the opaqueness is not incessantly attributed to high nitrogen content in the glass network [11,12]. The transparency issue of oxynitride glasses has been investigated [13-16], but with no significant progress toward obtaining nitrogen-enriched glasses with fully transparency [17-19]. One of the most common reasons for the opacity of the oxynitride glasses is the alleged precipitation of silicon $[13,16,20]$, which is due to the decomposition of $\mathrm{Si}_{3} \mathrm{~N}_{4}$ [21] at a temperature above $1600{ }^{\circ} \mathrm{C}$. Meanwhile, avoiding decomposition of $\mathrm{Si}_{3} \mathrm{~N}_{4}$ by applying low synthesis temperature, e.g., $1450{ }^{\circ} \mathrm{C}$, high transparent glasses have been obtained for some compositions. Silicon nitride ceramics also contain free silicon, generally, the higher the amount of Si, the darker the glasses/ceramics, and the less transparent glasses/ceramics are. Sharafat et al. $[5,22]$ reported that the Ca-containing SiON system reveals better transparency for the glasses containing high nitrogen contents. This is attributed to the use of high purity precursors and slow cooling rates resulting in improved transparency. Furthermore, it was found that the substituting of $\mathrm{Ca}$ with $\mathrm{Mg}$ in the $\mathrm{Ca}-\mathrm{Si}-\mathrm{O}-\mathrm{N}$ system enhances the transparency of the glasses. In contrast, silicon-free oxynitride glasses, e.g., $\mathrm{P}-\mathrm{O}-\mathrm{N}$-based, and oxynitride glasses prepared via sol-gel methods are transparent. Recently, Sharafat et al. [23-25] have reported amorphous transparent thin films in the nitrogen enrich $\mathrm{Mg} / \mathrm{Ca}-\mathrm{Si}-\mathrm{O}-\mathrm{N}$ systems prepared by reactive RF magnetron co-sputtering from $\mathrm{Mg} / \mathrm{Ca}$ and $\mathrm{Si}$ targets in an $\mathrm{N}_{2} / \mathrm{O}_{2} /$ Ar gas mixture. These thin films are free from elemental silicon and metallic silicides impurities, as found in bulk $\mathrm{Mg} / \mathrm{Ca}-\mathrm{Si}-\mathrm{O}-\mathrm{N}$ systems and contain an unprecedented amount of modifier and nitrogen. Furthermore, thin films in the $\mathrm{Mg} / \mathrm{Ca}-\mathrm{Si}-\mathrm{O}-\mathrm{N}$ systems have higher hardness, elastic moduli, and refractive index as compared to bulk glasses in the said systems of similar compositions.

Considering the growing interest in oxynitride glasses, the objective of this work is to provide information and formulate a reasonably complete and consistent description of microstructure and impurities in the nitrogen rich glasses in the $\mathrm{La}-\mathrm{Si}-\mathrm{O}-\mathrm{N}$ system.

\section{Experimental}

Preparation of $\mathrm{La}-\mathrm{Si}-\mathrm{O}-\mathrm{N}$ glasses was carried out using powder mixtures of $\mathrm{La}$ metal (ChemPure, 99.9\%, Karlsruhe, Germany), $\mathrm{Si}_{3} \mathrm{~N}_{4}$ (UBE, SNE10, Tokyo, Japan), and $\mathrm{SiO}_{2}$ (Aerosil 50, Hanau-Wolfgang, Geramny). Ten-gram batches of each composition were ground in a glovebox compartment under Ar atmosphere to avoid the mixture from oxidation. The mixtures were melted in niobium crucibles at $1650-1800{ }^{\circ} \mathrm{C}$, in a nitrogen atmosphere, using a radio frequency furnace. Further details on synthesis condition, composition, and characterisations are given in [1,2].

The obtained glasses were examined by X-ray powder diffraction (XRPD), using a Panalytical X'pert PRO MPD (Almelo, Netherlands) diffractometer and $\mathrm{CuK}_{\alpha 1}$ radiation. Samples were analysed by light microscope and scanning electron microscopy to observe the surface morphology. The microstructure examination was carried out using a Jeol (JSM 7000F, Tokyo, Japan) scanning electron microscope. Micrographs of the specimens were acquired in backscattered electron mode (BSE) to obtain compositional contrast. The cationic percentage compositions of glass and crystalline phases were evaluated through EDX point analyses, on polished and carbon-coated surfaces, ten (10) analyses on each sample, with a Si detector and a LINK INCA (Oxford Inc., High Wycombe, UK.) program system. $\mathrm{N}_{2}$ and $\mathrm{O}_{2}$ contents were determined by using combustion analysis with a Leco Detector (TV-436DR, Leoben, Austria) equipment. Raman spectroscopy measurement was performed with a dispersive confocal Raman microscope (Renishaw inVia, New Mills, UK.) 
using $633 \mathrm{~nm}$ laser excitation lines. The spectra were obtained in the range from 200 to $2200 \mathrm{~cm}^{-1}$ with a resolution of $2 \mathrm{~cm}^{-1}$, the sample spot size of the Raman microscope is $\sim 0.5 \mu \mathrm{m}$ in diameter. The surface topography of the glasses was characterised by atomic force microscopy (AFM) (Bruker, NanoScope Controller, Santa Barbara, CA, USA) in tapping mode for both height and phase image using an RTESPA $300^{\circ}$ probe. The analysis was performed on the freshly fracture surface of glass samples. The microstructure of the glass and silicide morphology were investigated by transmission electron microscopy (TEM) and electron energy-loss spectroscopy (EELS). For TEM observations, the bulk sample was plane-parallel ground, one-sided dimpled and polished to $\sim 20 \mu \mathrm{m}$ residual thickness, Argon ion beam polished $\left(2.5 \mathrm{kV}, 4^{\circ}\right.$ angle of glancing incidence), and selectively carbon coated [26]. Transmission electron microscopy (TEM) studies were carried out using a Hitachi TEM (H-8100 operated at $200 \mathrm{keV}$, equipped with EDXS, Krefeld, Germany) and a JEOL TEM (JEM 4010 operated at $400 \mathrm{keV}$ ). EELS analyses were performed using a dedicated scanning transmission electron microscope (VG HB501 UX, Tokyo, Japan) equipped with a cold field emission gun and a high-resolution electron energy-loss spectrometer (Gatan Enfina 1000, Pleasanton, CA, USA).

\section{Results and Discussion}

\subsection{Influence of Time and Temperature}

The glass-forming region and properties of $\mathrm{La}-\mathrm{Si}-\mathrm{O}-\mathrm{N}$ glasses were reported by Hakeem et al. [1,2]. These glasses were prepared by incorporating the La metal in the reaction mixture rather than using $\mathrm{La}_{2} \mathrm{O}_{3}$ - as typically used-with silicon nitride as the nitrogen source. The obtained glasses contained up to $62 \mathrm{e} / \mathrm{o}$ of La and $68 \mathrm{e} / \mathrm{o}$ of N, and showed a larger glass-forming region than previously reported [27-31]. The effect of time and temperature are, to a certain extent, interrelated. By increasing the temperature, the melting process speeds up and leads to high weight loss. The amounts of silicide did not show apparent variation with glass composition or preparation temperature.

\subsection{Influence of Raw Materials and Nitrogen Pressure}

All of the glass samples were prepared from a similar source of powders of La, $\mathrm{SiO}_{2}$, and $\mathrm{Si}_{3} \mathrm{~N}_{4}$ and using identical nitrogen pressure, i.e., one (1) atmospheric pressure. Therefore, it is difficult to ascertain the effects of raw materials and nitrogen pressure in the present study. However, Korgul et al. [12] concluded that the transparency of the glasses improved by using high-purity quartz powder instead of precipitated silica. Furthermore, it was observed that the substitution of $\mathrm{Si}_{3} \mathrm{~N}_{4}$ by $\mathrm{AlN}$ (in the SiAlON system) and increasing nitrogen pressure show no distinction improvement in the transparency. Sharafat et al. [4] reported glasses in the $\mathrm{Sr}-\mathrm{Si}-\mathrm{O}-\mathrm{N}$ system turn more transparent by using $\mathrm{SrD}_{2}$ rather than $\mathrm{Sr}$ metal as a modifier. Furthermore, the glasses made by using $\mathrm{SrD}_{2}$ contain much smaller amounts of $\mathrm{Sr}$ silicides as compared to the glasses prepared by Sr metal. Pasto et al. [32] reported that the origin of the impurities was in the raw materials; additionally, impurities were picked up during powder processing and melting. Iron is probably the most common impurity found in the batch material for glass (impurity from the precursors) and can readily oxidise silicon nitride at quite low temperatures to form $\mathrm{FeSi}_{2}$. Furthermore, decomposition was not noticeably diminished when using high-purity $\mathrm{Si}_{3} \mathrm{~N}_{4}$ as a batch component. As mentioned earlier that no iron impurities were present in the used raw materials for the preparation of nitrogen-enriched glasses in the $\mathrm{La}-\mathrm{Si}-\mathrm{O}-\mathrm{N}$ system, both SEM and TEM investigation endorse no existence of iron silicide in the present glasses.

\subsection{Observation of Interface between Glass and Niobium Crucible}

All the glasses were prepared by standard procedures, as described in the experimental section. It was observed that there is no reaction between $\mathrm{La}-\mathrm{Si}-\mathrm{O}-\mathrm{N}$ melt and niobium crucible used in the study, although the melt did adhere to the surface of the crucible. Similarly, no reaction between the melt and $\mathrm{Nb}$ crucible was observed in 
other $\mathrm{AE}-\mathrm{Si}-\mathrm{O}-\mathrm{N}(\mathrm{AE}=\mathrm{Mg}, \mathrm{Ca}, \mathrm{Sr}, \mathrm{Ba})[3,4,22,33]$ systems prepared by a similar synthesis route as described for $\mathrm{La}-\mathrm{Si}-\mathrm{O}-\mathrm{N}$ glasses. However, it was observed that the $\mathrm{La}-\mathrm{Si}-\mathrm{Al}-\mathrm{O}-\mathrm{N}$ glass in which $\mathrm{AlN}$ was added does react with the $\mathrm{Nb}$ crucible and some of AlN remained undissolved in the liquid because of its strong bonding and stability of the AlN and perhaps much longer holding time required for AlN to dissolve into the liquid phase. Therefore, aluminium had to be added in oxide (and perhaps in metallic) form, i.e., as $\mathrm{Al}_{2} \mathrm{O}_{3}$ instead of $\mathrm{AlN}$, as an admixture to the composition. Experimental observation indicates that $\mathrm{Al}_{2} \mathrm{O}_{3}$ reacts and dissolves into the liquid much faster than AlN. Figure 1 reveals some undissolved AlN near the crucible wall. It is thus easier to dissolve $\mathrm{Al}_{2} \mathrm{O}_{3}$ than AlN in the La-Si-Al-O-N system. Recently, Natalia et al. [34] reported the dissolution of $\mathrm{Nb}$ metal from $\mathrm{Nb}$ crucible in the phosphorus-based oxynitride glasses. The addition of $\mathrm{Al}_{2} \mathrm{O}_{3}$ into the $\mathrm{La}-\mathrm{Si}-\mathrm{O}-\mathrm{N}$ system showed that the glasses can be prepared at lower temperature and in a shorter time. Furthermore, the addition of $\mathrm{Al}$ to the $\mathrm{La}-\mathrm{Si}-\mathrm{O}-\mathrm{N}$ system enhances transparency and minimises losses of components during preparation.

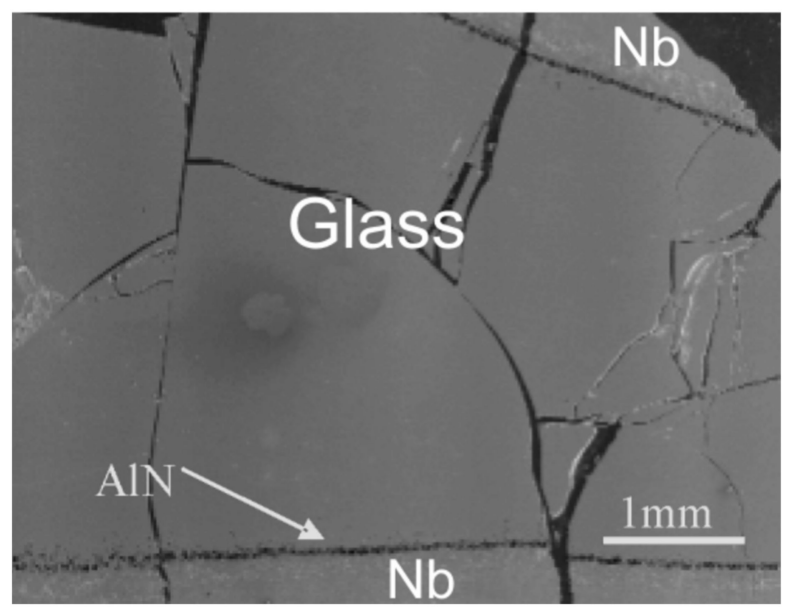

Figure 1. SEM image $\mathrm{La}-\mathrm{Al}-\mathrm{Si}-\mathrm{O}-\mathrm{N}$ glass prepared in the $\mathrm{Nb}$ crucible and $\mathrm{AlN}$ as a starting powder, the arrow indicating the wall of the $\mathrm{Nb}$ crucible [9].

\subsection{Optical Microscopy Observations}

Light microscopy was used to examine the surface of polished glass samples. Most of the glasses were found to be opaque and generally had a brown colouration and reflecting white spots, as shown in Figure 2a. Additionally, further experiments confirm that glasses contain spherical La silicide $\left(\mathrm{LaSi}_{2}\right)$ particles in the matrix. The amount was estimated in the range of around 2 to $4 \mathrm{vol} . \%$ and varied upon the starting composition. There was no elemental silicon observed by the light microscope and SEM analysis. Figure $2 b$ shows the character of the distribution of opaque grains. The glass samples contain a very high frequency of equidimensional rounded opaque grains reaching sizes of a few microns, although most of them are much smaller. The opaque grains are unevenly distributed, with larger, more separated grains in the more transparent parts of the glass. In contrast, dusty impregnations of microscopic opaque particles occur in the dark-coloured parts of the glass.

\subsection{Scanning Electron Microscopy}

SEM observations showed that glasses have homogeneous microstructures, indicating a lack of substructural features, as shown in Figure 3. However, the glasses do contain small amounts of La silicide (mostly spherical particles), as noticed by the optical microscopic analysis as well. The La-Si interaction is complex. It might occur during synthesis, as part of the initial $\mathrm{Si}_{3} \mathrm{~N}_{4}$ and $\mathrm{SiO}_{2}$ is reduced at an early stage to form a silicide with $\mathrm{La}$ metal. This might be ascribed to one of the following two mechanisms: (a) the direct reaction between $\mathrm{La}$ metal and $\mathrm{Si}_{3} \mathrm{~N}_{4}$ to produce lanthanum silicide $\left(\mathrm{La}_{\mathrm{x}} \mathrm{Si}_{\mathrm{y}}\right)$ and nitrogen 
or (b) the reaction of lanthanum nitride + silicon, with a subsequent reaction of La and $\mathrm{Si}$. At high temperature and longer holding time, the $\mathrm{La}_{x} \mathrm{Si}_{\mathrm{y}}$ gradually dissolves into the glass. According to the lanthanum-silicon phase diagram [35], $\mathrm{LaSi}_{2}$ melts at $1730{ }^{\circ} \mathrm{C}$ and $\mathrm{La}_{3} \mathrm{Si}_{2}$ melts at $1470{ }^{\circ} \mathrm{C}$. Additionally, few compositions had a lower proportion of silicide precipitation, which indicates that the formation and the quantities of silicides largely depend on the synthesis route and heat treatment procedure and not much on nitrogen concentration present in the stoichiometry.
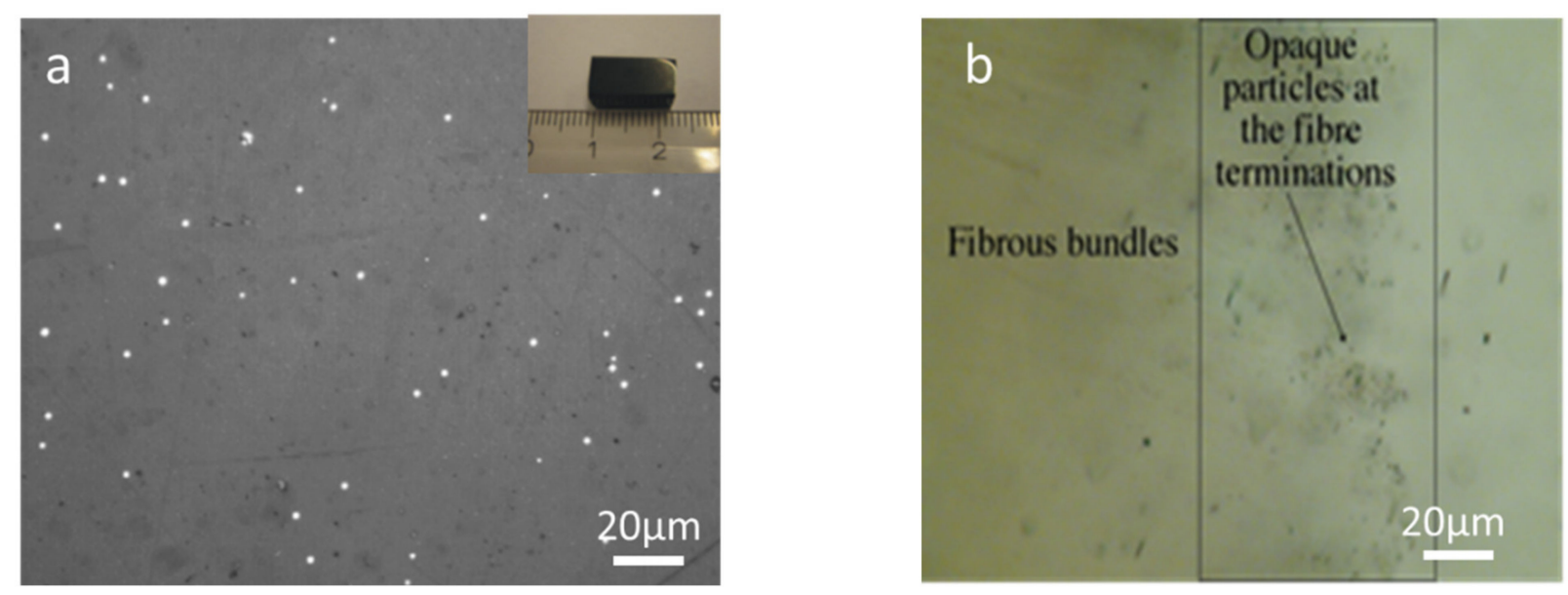

Figure 2. Optical micrographs were showing the presence of (a) La silicides (white spots) in nitrogen-enriched La-Si-O-N glass and a polished glass piece of (inset). (b) Fibrous bundles in $\mathrm{La}-\mathrm{Si}-\mathrm{O}-\mathrm{N}$ glass.

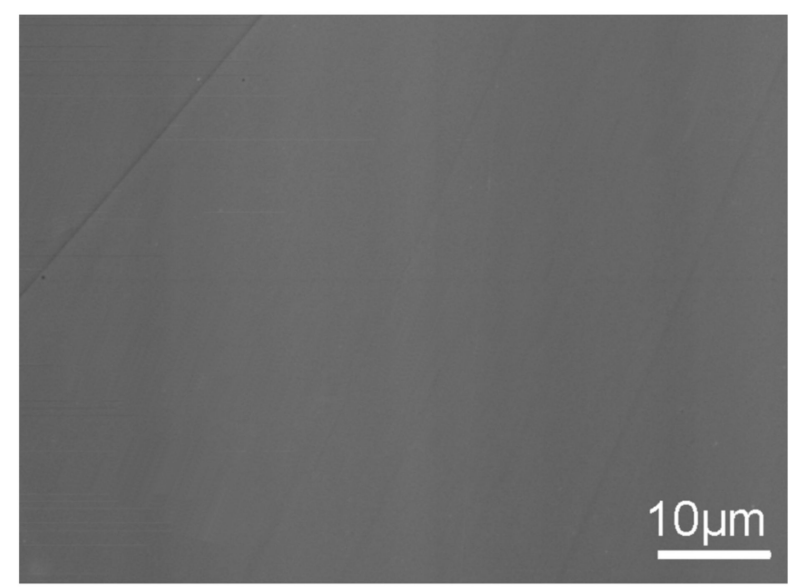

Figure 3. SEM image of a homogeneous glass surface with no apparent impurities [9].

Figure 4 shows SEM micrographs of the different morphologies and crystalline phases in the partially crystalline glass matrix. Glass sample gives weak X-ray reflections according to the XRPD pattern. However, the SEM image Figure 4a shows the presence of two glass phases by BSE compositional analysis: oxygen-rich La oxynitride phases and black coloured undissolved $\mathrm{Si}_{3} \mathrm{~N}_{4}$. For amorphous or poorly crystallised samples, as in the $\mathrm{La}-\mathrm{Si}-\mathrm{O}-\mathrm{N}$ system, the determination of weak X-ray reflections is complicated due to the presence of a high-intensity background (the result of inelastic scattering), leading to an underestimation of the size of crystallites. SEM image Figure $4 \mathrm{~b}$ shows two glass phases and silicide particles (white spherical), the majority of the silicides have $\mathrm{LaSi}_{2}$ phase. Micrograph Figure $4 \mathrm{c}$ shows the growth of dendrites and Figure $4 \mathrm{~d}$ further growth of the needle-like structure of a crystalline phase. Nitrogen-enriched La-containing $\mathrm{SiON}$ glasses can be described as a mixture of amorphous $\mathrm{SiO}_{2}$ and crystalline $\mathrm{LaSi}_{2}$, thus implying that phase separation occurred according to the microstructure viewpoint. Moreover, it was observed that the 
degree of crystallisation and the crystal sizes decrease with increasing nitrogen content. Generally, nitrogen rich glasses containing a high amount of silicides have Poisson's ratio ranging from 25 to 36 , resemble those of metallic glasses having Poisson's ratio of $\sim 40$.
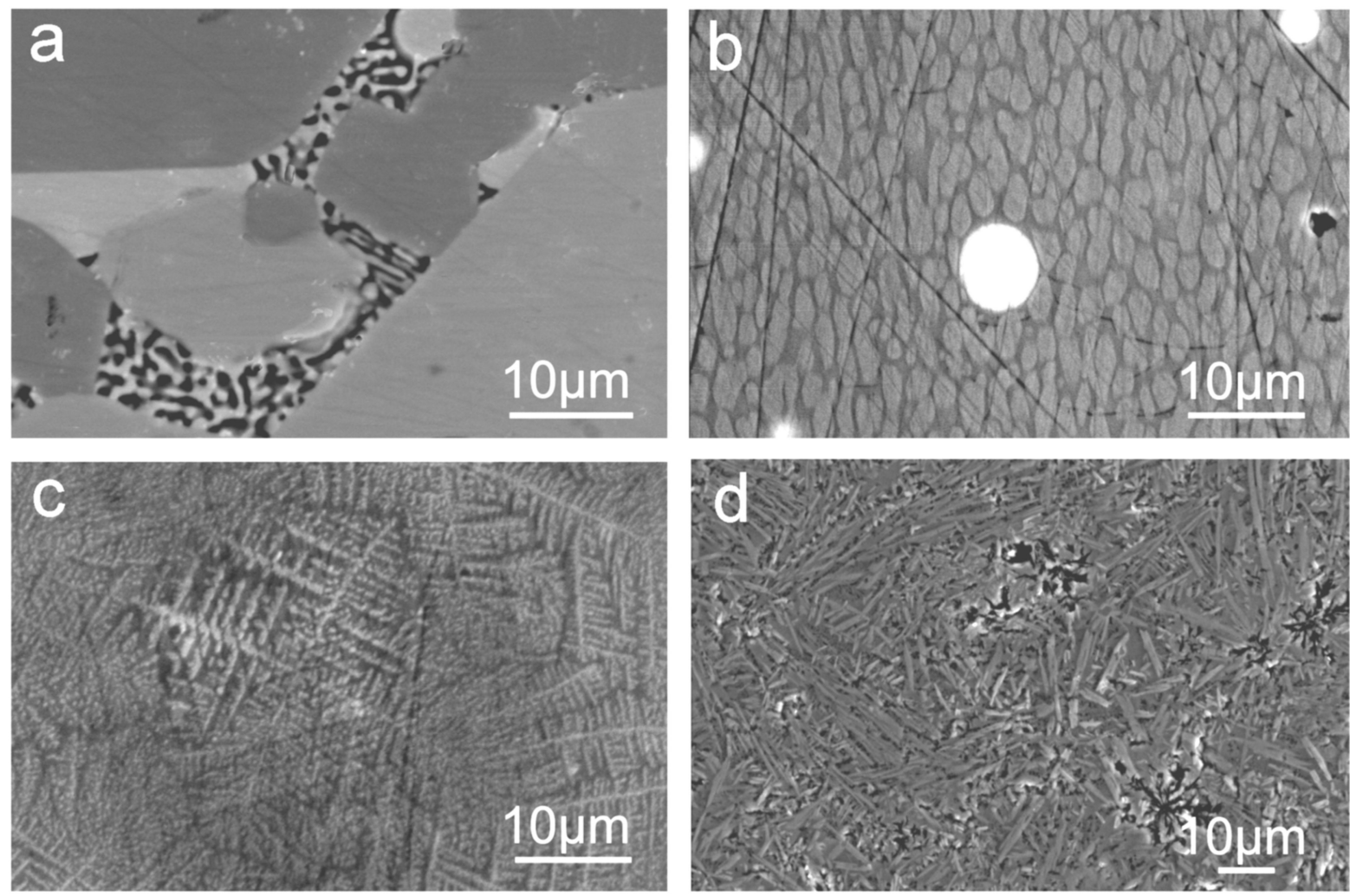

Figure 4. SEM images show (a) two phases in the La-Si-O-N glass matrix, (b) spherical La silicide-white, (c) dendritic growth in the glass and (d) needle- or lath-like crystalline morphologies [9].

\subsection{Raman Spectroscopy}

Raman spectra show that the glasses in the $\mathrm{La}-\mathrm{Si}-\mathrm{O}-\mathrm{N}$ system contain elemental $\mathrm{Si}$ and LaSi impurities. It was thus hypothesized that the absence of any signal in the XRD spectrum of these impurities is due to their size and quality effect. However, according to Raman studies, an elemental Si gives a sharp peak at $522 \mathrm{~cm}^{-1}$. The intensity of the Si peaks decreases with the increasing $\mathrm{N}$ content, and no Si peaks are observed for glasses with $\mathrm{N}$ contents above $\sim 40 \mathrm{e} / \mathrm{o}$. The spectra show a high background of fluorescence, which increases with increasing $\mathrm{N}$ and La contents, implying that the recorded spectra have, in general, a poorer quality for high $\mathrm{N}$ content glasses. Rouxel et al. [11] have reported that the strong luminescence observed in the oxynitride glasses could be due to silicon clusters of less than $7 \mathrm{~nm}$ in diameter. Figure 5 shows the Raman spectra of the La silicide particle.

\subsection{Atomic Force Microscopy (AFM), Transmission Electron Microscopy (TEM) and Electron Energy-Loss Spectroscopy (EELS) Analysis}

The surface topography of $\mathrm{La}-\mathrm{Si}-\mathrm{O}-\mathrm{N}$ glasses was investigated by AFM on the freshly fractured surfaces. The surface topography of all the studied glasses is smooth and uniform with a surface roughness value lower than $1 \mathrm{~nm}$, which is close to the roughness of known silicate glasses. Figure 6 shows a uniform, defect-free and featureless structure, typical for amorphous materials with extremely fine grains. 


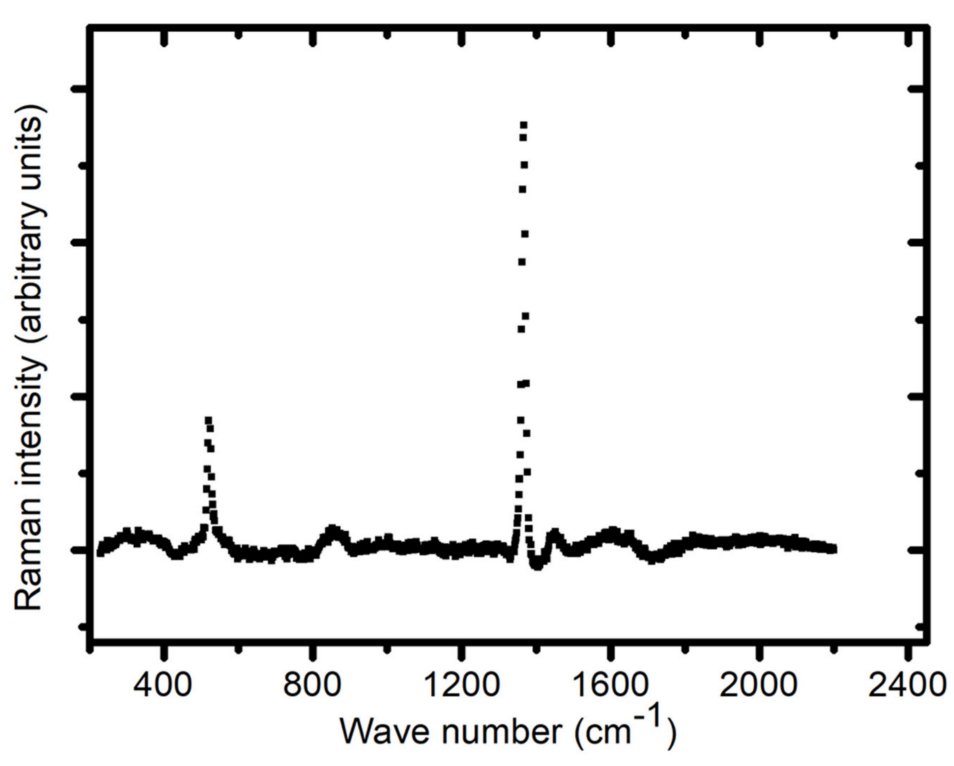

Figure 5. Raman spectra of silicide particles in $\mathrm{La}-\mathrm{Si}-\mathrm{O}-\mathrm{N}$ glass.
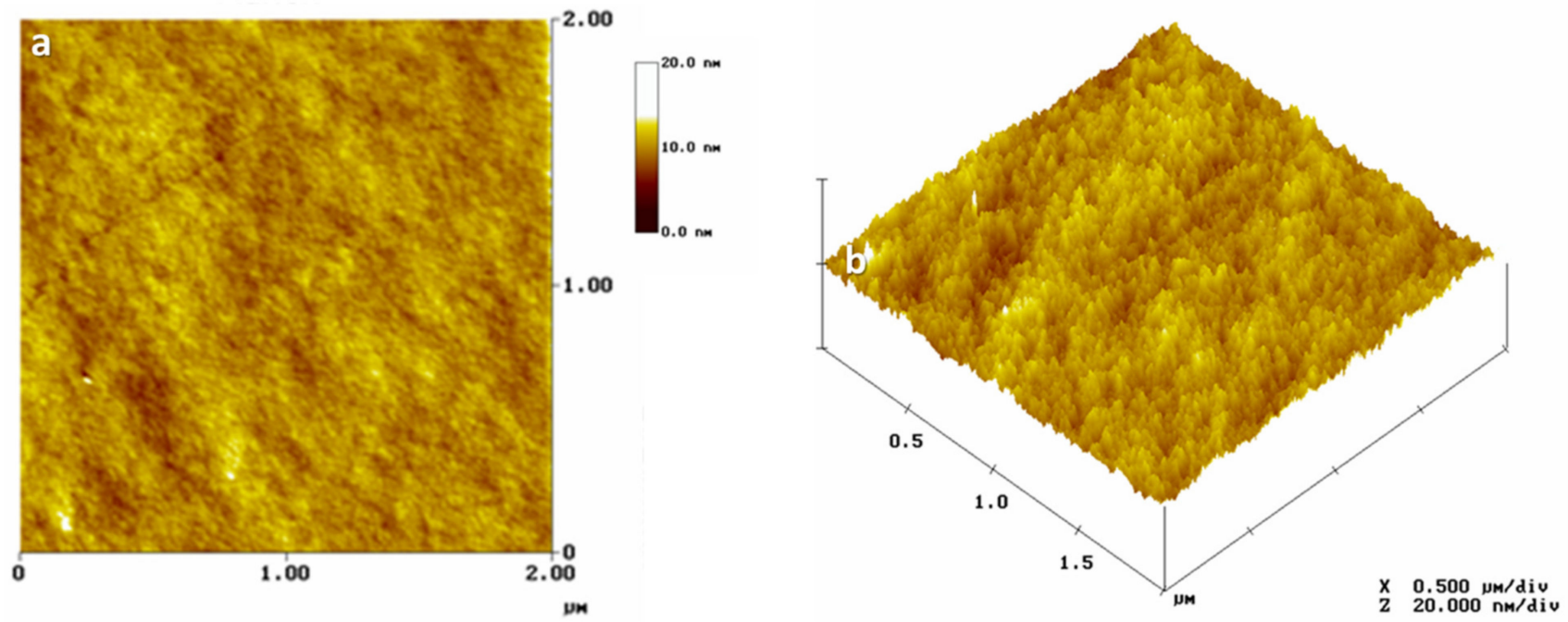

Figure 6. Atomic force microscopy images (a) $2 \mathrm{D}$ and (b) 3D, showing smooth and featureless morphology of $\mathrm{La}-\mathrm{Si}-\mathrm{O}-\mathrm{N}$ glass.

The HRTEM images in Figure 7 show homogenous microstructure glasses with no porosity.

There is no evidence of substructural features in the glassy region and selected area electron diffraction (SAED) patterns confirmed the amorphous nature of the sample. Figure 8a shows the microstructure of the silicide particles of La silicide and Si-enriched particles. The majority of the La silicides are spherical and have uniform compositions. However, some of the La silicides have prominent internal structures, having entrapped particles of Si-rich phase(s), which might be $\mathrm{Si}_{3} \mathrm{~N}_{4}$ or $\mathrm{Si}$, and $\mathrm{La}$ enriches in the surrounding glass (Figure $8 b, c)$. The diameter of the particles is somewhere between 1 and $5 \mu \mathrm{m}$, as also observed by optical microscopy investigation. These observations indicate that the lanthanum silicides steadily dissolve during the synthesis. The amounts of silicide showed no apparent variation with glass composition. However, some of the samples, as shown in Figure 9, show phase separation in the length scale of 10 to $30 \mathrm{~nm}$. 


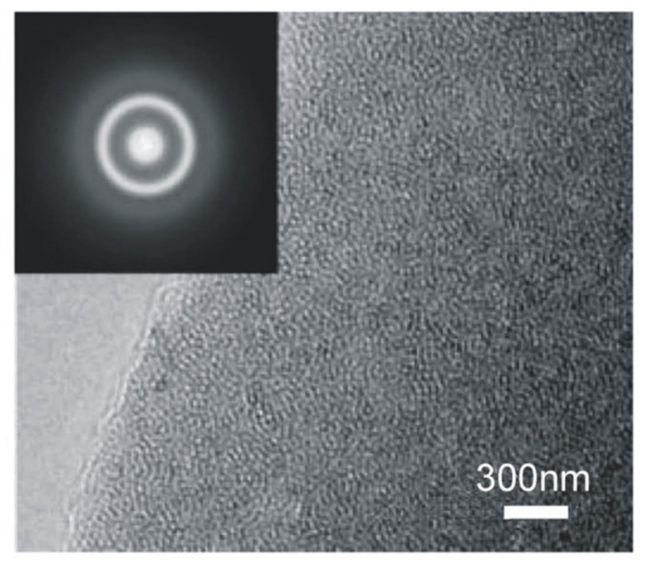

Figure 7. High-resolution transmission electron microscope image with the corresponding selected area diffraction pattern (inset) for $\mathrm{La}-\mathrm{Si}-\mathrm{O}-\mathrm{N}$ glass [9].

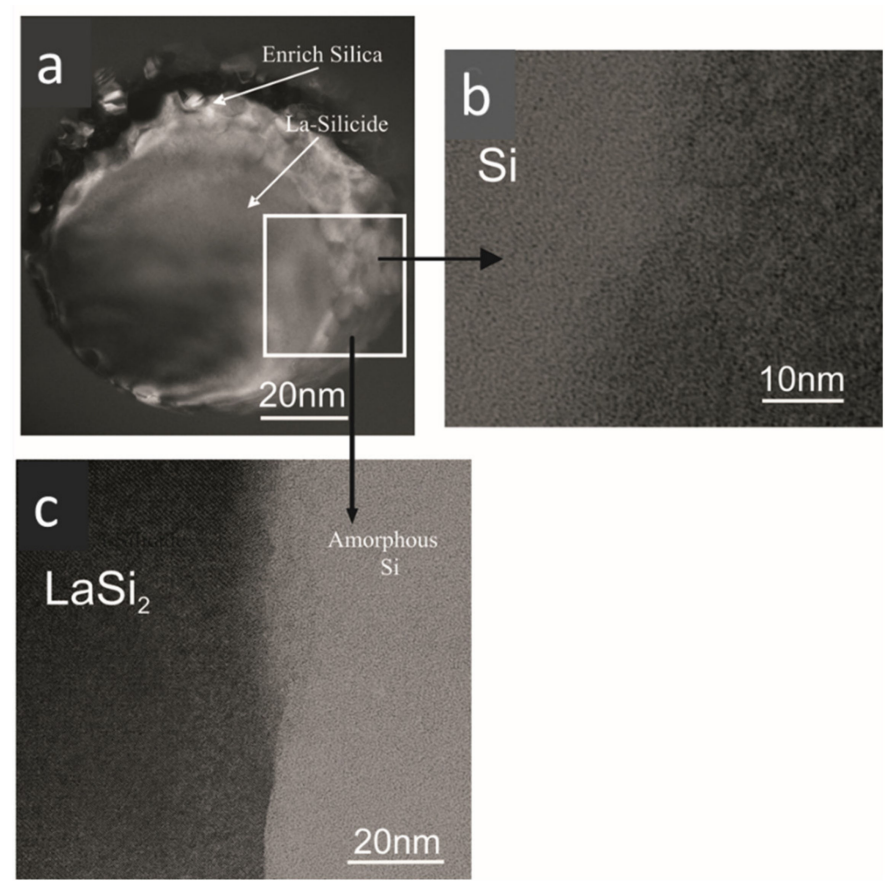

Figure 8. Transmission electron micrographs showing (a) silicide particle and (b,c) enlarged areas of Si and La-silicide, respectively [9].

The Raman spectra, as shown in Figure 5, show a sharp and intense absorption band characteristic from elemental silicon at $520 \mathrm{~cm}^{-1}$. The fact that no crystallinity was detected by X-ray diffraction might be due to the deficient amounts of elemental Si present in the glass matrix. Even a small amount of free silicon probably partly hinders the glass transparency, with another possible cause being the clustering or nano-phase separation evidenced by TEM, as shown in Figure 9.

In Figure 10a-c, EELS spectra from a sample of $\mathrm{La}-\mathrm{Si}-\mathrm{O}-\mathrm{N}$ glass show the presence of silicon on the edges of the precipitate. The interface between Si and glass shows no fringes indicating any ordered structure, but at the interface between $\mathrm{Si}$ and precipitate, ordered fringes in silicon can be seen. Figure 11 shows the EELS spectra of the amorphous region and no evidence of compositional fluctuation along with the $100 \mathrm{~nm}$ line scan. The size of free Si is less than $100 \mathrm{~nm}$ in diameter. These particles were not visible under a light microscope nor by SEM. These observations lead to the conclusion that the more nitrogen is incorporated in the glass network and the more fragile the glass becomes. Additionally, it is suggested that nitrogen favours the formation of a heterogeneous network at the 
nanometre scale and leads to a network structure with weak channels, resembling the ones proposed by Greaves et al. [36] and acting as a lubricant between the clusters.

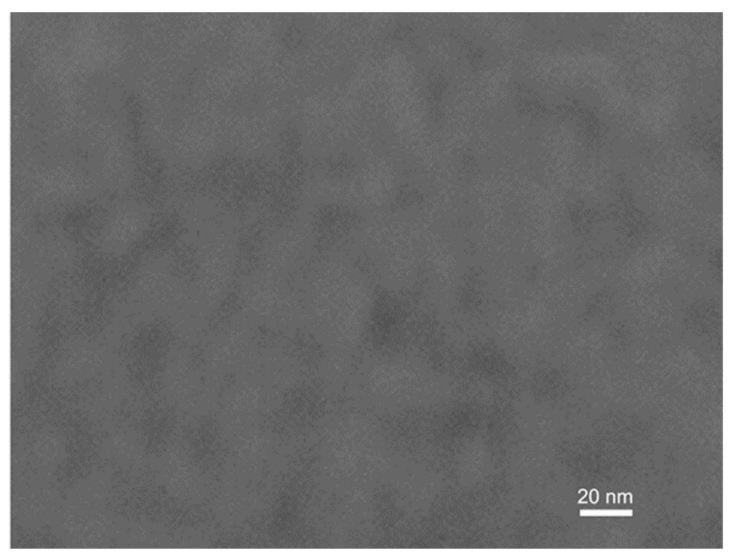

Figure 9. TEM image of the $\mathrm{La}-\mathrm{Si}-\mathrm{O}-\mathrm{N}$ glass indicating some features of either phase-separation or compositional difference in the range of $\sim 10$ to $30 \mathrm{~nm}$ [9].
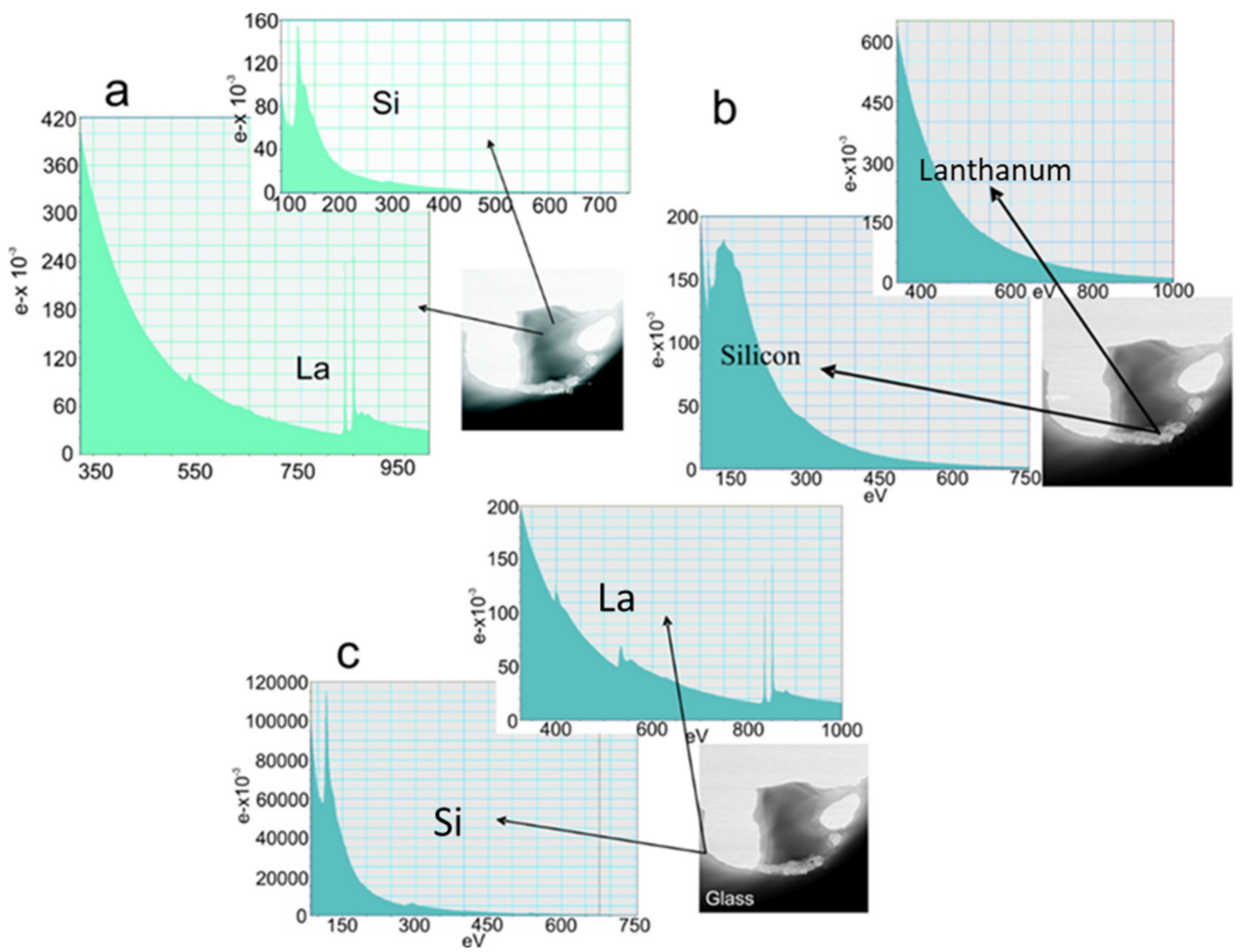

Figure 10. TEM (EELS analysis) images (a) core of the ppt, (b) edge of the ppt, and (c) edge of the glass [9].

\subsection{Comparison with $\mathrm{La}-\mathrm{Si}-\mathrm{O}-\mathrm{N}$ Thin Films}

For comparison purposes, thin films in the $\mathrm{La}-\mathrm{Si}-\mathrm{O}-\mathrm{N}$ system were grown on soda-lime glass and sapphire substrates by RF magnetron sputtering apparatus. For the deposition, $50 \mathrm{~mm}$ diameter targets of lanthanum (purity 99.95\%) and silicon (purity 99.99\%) were used in an ultra-high vacuum (UHV) deposition system. For reactive sputtering, a mixture of $\operatorname{Ar}(31.4 \mathrm{sccm})$, nitrogen $(8 \mathrm{sccm})$ and oxygen $(0.6 \mathrm{sccm})$ was used, with a total gas flow of $40 \mathrm{sccm}$. The deposition time was $2 \mathrm{~h}$. The compositional analysis by EDX and X-ray photoelectron spectroscopy (XPS) confirmed that obtained films contain a high amount of La and N. As shown in Figure 12, thin films in the $\mathrm{La}-\mathrm{Si}-\mathrm{O}-\mathrm{N}$ system are 
optically transparent and free from metallic impurities as compared to bulk $\mathrm{La}-\mathrm{Si}-\mathrm{O}-\mathrm{N}$ glass. A fair comparison of La containing thin films and bulk glasses is difficult due to differing synthesis techniques, stoichiometry, and dimensionality of the disordered network. In summary, it is possible to obtained optical transparent glasses with high nitrogen content by optimising the process parameters and the selection of the precursors.

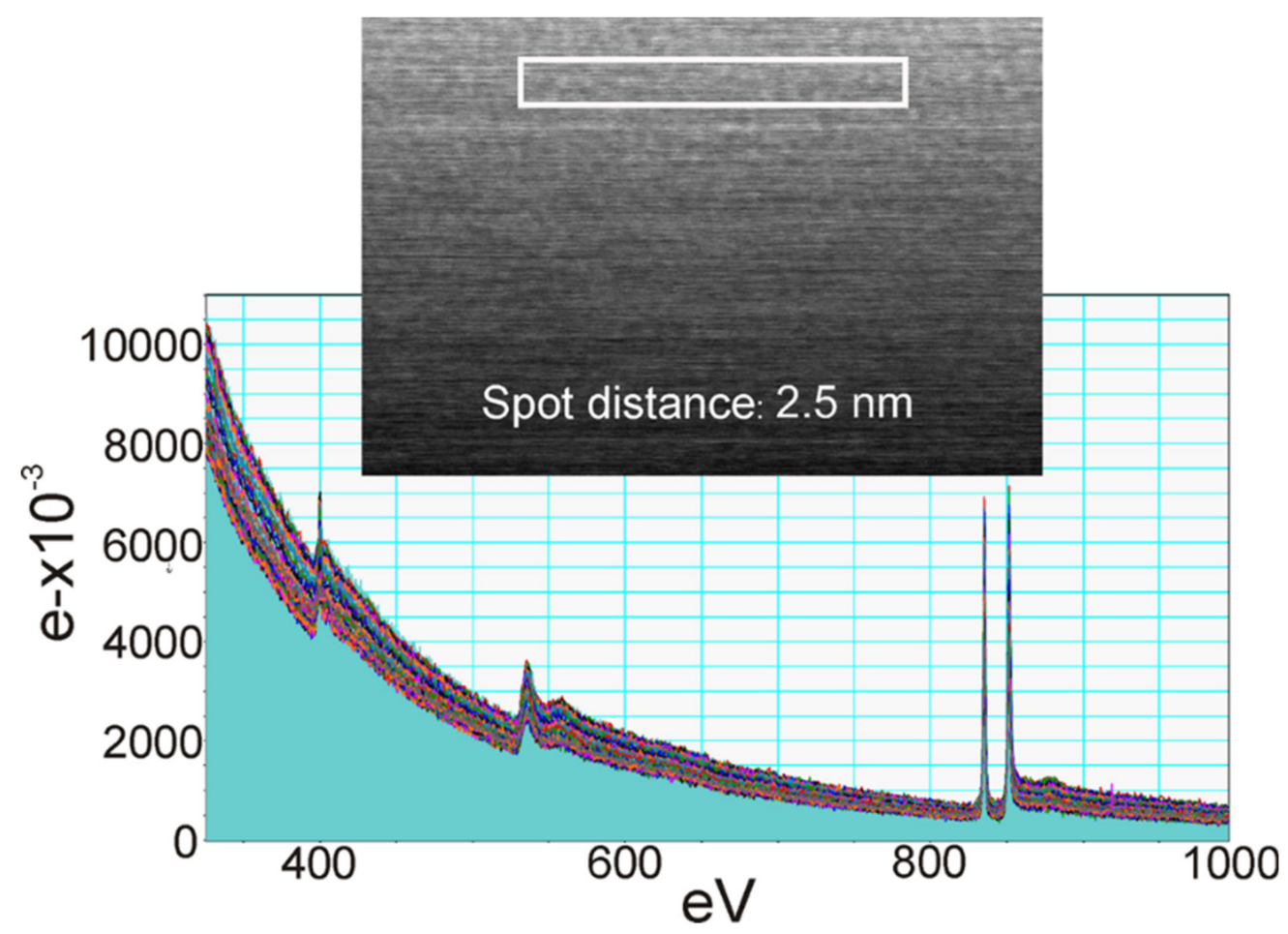

Figure 11. EELS spectra of compositional fluctuation along with the $100 \mathrm{~nm}$ line scan [9].

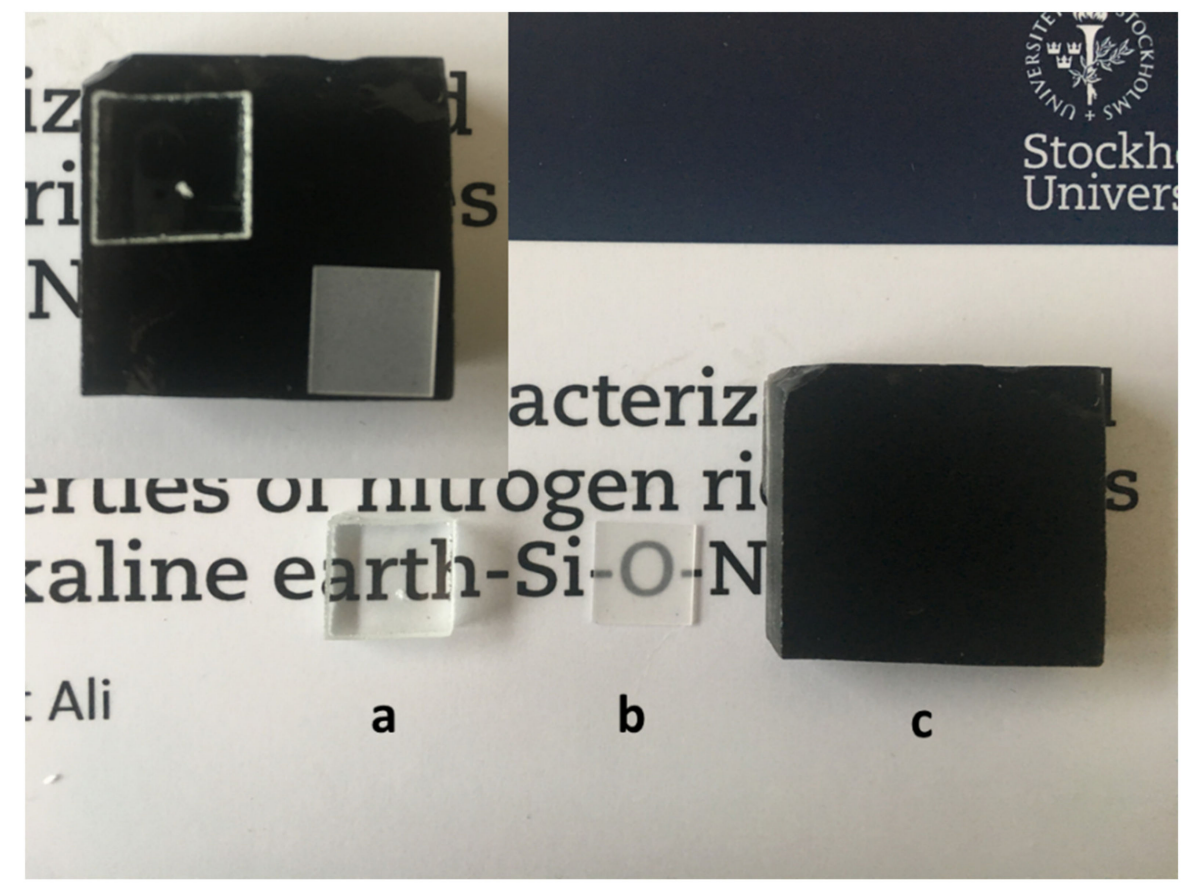

Figure 12. Photograph of the (a) coated float glass with $\mathrm{La}-\mathrm{Si}-\mathrm{O}-\mathrm{N}$ thin films (the dot on the backside is a reference for not coated side), (b) sapphire substrate coated with $\mathrm{La}-\mathrm{Si}-\mathrm{O}-\mathrm{N}$ thin film and (c) bulk oxynitride glass prepared by melt-quenching technique. 


\section{Conclusions}

The use of oxynitride glasses in optical applications depends on the minimisation or elimination of metallic silicides and free silicon defects that arise during synthesis. Metallic silicide and elemental silicon impurities were studied in nitrogen-rich $\mathrm{La}-\mathrm{Si}-\mathrm{O}-\mathrm{N}$ glasses by optical, SEM and TEM microscopy. It was ascertained that these impurities are the main reason for the non-transparency of these glasses. The higher the amount of La silicides and free $\mathrm{Si}$ contents, the darker the glasses. The size of the La silicide was found to be below $1 \mu \mathrm{m}$, and its structure is amorphous or poorly crystalline. The elemental Si has a size of less than $100 \mathrm{~nm}$. The quantities of elemental Si are much lower than the silicides. Nitrogen rich $\mathrm{La}-\mathrm{Si}-\mathrm{O}-\mathrm{N}$ glasses show structural heterogeneities at the atomic or molecular scale. In contrast, nitrogen rich, thin films in the $\mathrm{La}-\mathrm{Si}-\mathrm{O}-\mathrm{N}$ system are transparent and free from impurities. Furthermore, these thin films are smooth and homogenous. Impurities such as metal silicide and elemental silicon can be minimised by developing a low-temperature processing route, the use of AIN instead of $\mathrm{Si}_{3} \mathrm{~N}_{4}$ as the source of nitrogen and use of high purity raw materials. However, much further work is needed to confirm (or possibly disprove) these statements.

Author Contributions: Conceptualization; A.S.H., S.A.; Methodology; A.S.H., S.A.; Validation; A.S.H., S.A., Q.A.D., T.H., A.A.K., B.J.; Formal analysis; A.S.H., S.A., Q.A.D.; Investigation; A.S.H., S.A., T.H.; Resources; A.S.H., S.A., T.H.; Data curation; A.S.H., S.A.; Writing-original draft preparation; A.S.H., S.A., Q.A.D.; Writing-review and editing; A.S.H., S.A., Q.A.D., T.H., A.A.K., B.J.; Visualization; A.S.H., S.A.; Supervision; A.S.H., S.A.; Project administration; A.S.H., S.A.; Q.A.D.; Funding acquisition; A.S.H., S.A., Q.A.D. All authors have read and agreed to the published version of the manuscript.

Funding: This research was funded by, Deanship of Scientific Research (DSR) at King Fahd University of Petroleum \& Minerals (KFUPM) through project No. DF191020.

Institutional Review Board Statement: Not applicable.

Informed Consent Statement: Not applicable.

Data Availability Statement: Not applicable.

Conflicts of Interest: The authors declare no conflict of interest.

\section{References}

1. Hakeem, A.S.; Grins, J.; Esmaeilzadeh, S. La-Si-O-N glasses-Part, I. Extension of the glass forming region. J. Eur. Ceram. Soc. 2007, 27, 4773-4781. [CrossRef]

2. Hakeem, A.S.; Grins, J.; Esmaeilzadeh, S. La-Si-O-N glasses-Part II: Vickers hardness and refractive index. J. Eur. Ceram. Soc. 2007, 27, 4783-4787. [CrossRef]

3. Sharafat, A.; Grins, J.; Esmaeilzadeh, S. Glass-forming region in the Ca-Si-O-N system using CaH $\mathrm{C}_{2}$ as Ca source. J. Eur. Ceram. Soc. 2008, 28, 2659-2664. [CrossRef]

4. Sharafat, A.; Forslund, B.; Grins, J.; Esmaeilzadeh, S. Formation and properties of nitrogen rich strontium silicon oxynitride glasses. J. Mater. Sci. 2009, 44, 664-670. [CrossRef]

5. Sharafat, A.; Grins, J.; Esmaeilzadeh, S. Hardness and refractive index of Ca-Si-O-N glasses. J. Non Cryst. Solids 2009, 355, 301-304. [CrossRef]

6. Leonova, E.; Hakeem, A.S.; Jansson, K.; Stevensson, B.; Shen, Z.; Grins, J.; Esmaeilzadeh, S.; Edén, M. Nitrogen rich La-Si-Al-O-N oxynitride glass structures probed by solid state NMR. J. Non-Cryst. Solids 2008, 354, 49-60. [CrossRef]

7. Hakeem, A.S.; Daucé, R.; Leonova, E.; Edén, M.; Shen, Z.; Grins, J.; Esmaeilzadeh, S. Silicate Glasses with Unprecedented High Nitrogen and Electropositive Metal Contents Obtained by Using Metals as Precursors. Adv. Mater. 2005, 17, 2214-2216. [CrossRef]

8. Hakeem, A.S.; Ali, S.; Jonson, B. Preparation and properties of mixed La-Pr silicate oxynitride glasses. J. Non Cryst. Solids 2013, 368, 93-97. [CrossRef]

9. Hakeem, A.S. Novel Route of Oxynitride Glass Synthesis and Characterisation of Glasses in the Ln-Si-O-N and Ln-Si-Al-O-N Systems. Ph.D. Thesis, Stockholm University, Stockholm, Sweden, 2007.

10. Höche, T.; Deckwerth, M.; Rüssel, C. Partial Stabilization of Tetragonal Zirconia in Oxynitride Glass-Ceramics. J. Am. Ceram. Soc. 1998, 81, 2029-2036. [CrossRef]

11. Rouxel, T.; Piriou, B. Free silicon and crystallization in silicon nitride based ceramics and in oxynitride glasses. J. Appl. Phys. 1996, 79, 9074-9079. [CrossRef]

12. Korgul, P.; Thompson, D.P. The transparency of oxynitride glasses. J. Mater. Sci. 1993, 28, 506-512. [CrossRef] 
13. Messier, D.R.; Deguire, E.J. Thermal-Decomposition in the System Si-Y-Al-O-N. J. Am. Ceram. Soc. 1984, 67, 602-605. [CrossRef]

14. Murakami, Y.; Yamamoto, H. Properties of Oxynitride Glasses in the Ln-Si-Al-O-N Systems (Ln = Rare-Earth). Nippon Seramikkusu Kyokai Gakujutsu Ronbunshi-J. Ceram. Soc. Jpn. 1994, 102, 231-236. [CrossRef]

15. Hakeem, A.S.; Khan, M.; Ahmed, B.A.; Al Ghanim, A.; Patel, F.; Ehsan, M.A.; Ali, S.; Laoui, T.; Ali, S. Synthesis and characterization of alkaline earth and rare earth doped sialon ceramics by spark plasma sintering. Intern. J. Refract. Metal. and Hard Mater. 2021, 97, 1-12. [CrossRef]

16. Jack, K.H. The Role of Additives in the Densification of Nitrogen Ceramics. Final Tech Rept, European Research Office, US Army, Grant No DAERO-76-G-067. 1979. Available online: https://apps.dtic.mil/sti/citations/ADA116581 (accessed on 15 June 2021).

17. Zhong, J.S.; Gao, H.B.; Yuan, Y.J.; Chen, L.F.; Chen, D.Q.; Ji, Z.G. Eu ${ }^{3+}$-doped double perovskite-based phosphor-in-glass color converter for high-power warm w-LEDs. J. Alloy. Compd. 2018, 735, 2303-2310. [CrossRef]

18. Muñoz, F.; Jiménez-Riobóo, R.J.; Balda, R. Chemical and structural heterogeneities in Nd-doped oxynitride phosphate laser glasses. J. Alloy. Compd. 2020, 816, 152657. [CrossRef]

19. Navrotsky, A. Thermochemical studies of nitrides and oxynitrides by oxidative oxide melt calorimetry. J. Alloy. Compd. 2001, 321, 300-306. [CrossRef]

20. Messier, D.R.; Broz, A. Microhardness and Elastic-Moduli of Si-Y-Al-O-N Glasses. J. Am. Ceram. Soc. 1982, 65, C123. [CrossRef]

21. Greskovich, C.; Prochazka, S. Stability of $\mathrm{Si}_{3} \mathrm{~N}_{4}$ and Liquid Phase(S) during Sintering. J. Am. Ceram. Soc. 1981, 64, C96-C97. [CrossRef]

22. Sharafat, A.; Grins, J.; Esmaeilzadeh, S. Properties of high nitrogen content mixed alkali earth oxynitride glasses $\left(\mathrm{AE}_{(\mathrm{x})} \mathrm{Ca}_{(1-\mathrm{x}))(1.2(1))} \mathrm{SiO}_{1.9(1)} \mathrm{N}_{0.86(6)}, \mathrm{AE}=\mathrm{Mg}, \mathrm{Sr}, \mathrm{Ba}\right.$. J. Non Cryst. Solids 2009, 355, 1259-1263. [CrossRef]

23. Sharafat, A.; Paul, B.; Magnusson, R.; Greczynski, G.; Broitman, E.; Jonson, B.; Eklund, P.; Birch, J. Novel transparent MgSiON thin films with high hardness and refractive index. Vacuum 2016, 131, 1-4.

24. Ali, S.; Paul, B.; Magnusson, R.; Broitman, E.; Jonson, B.; Eklund, P.; Birch, J. Synthesis and characterization of the mechanical and optical properties of $\mathrm{Ca}-\mathrm{Si}-\mathrm{O}-\mathrm{N}$ thin films deposited by RF magnetron sputtering. Surf. Coat. Technol. 2017, 315, 88-94. [CrossRef]

25. Sharafat, A.; Paul, B.; Magnusson, R.; Ekström, E.; Pallier, C.; Jonson, B.; Eklund, P.; Birch, J. Optical and mechanical properties of amorphous $\mathrm{Mg}-\mathrm{Si}-\mathrm{O}-\mathrm{N}$ thin films deposited by reactive magnetron sputtering. Surf. Coat. Technol. 2019, $372,9-15$.

26. Höche, T.; Gerlach, J.W.; Petsch, T. Static-Charging Mitigation and Contamination Avoidance by Selective Carbon Coating of TEM Samples. Ultramicroscopy 2006, 106, 981-985. [CrossRef] [PubMed]

27. Lofaj, F.; Hvizdos, P.; Dorcakova, F.; Satet, R.; Hoffmann, M.J.; de Arellano-Lopez, A.R. Indentation moduli and microhardness of RE-Si-Mg-O-N glasses ( $\mathrm{RE}=\mathrm{Sc}, \mathrm{Y}, \mathrm{La}, \mathrm{Sm}, \mathrm{Yb}$ and Lu) with different nitrogen content. Mater. Sci. Eng. A Struct. Mater. Prop. Microstruct. Process. 2003, 357, 181-187. [CrossRef]

28. Zhang, E.; Liddell, K.; Thompson, D.P. Glass forming regions and thermal expansion of some $\mathrm{Ln}-\mathrm{Si}-\mathrm{Al}-\mathrm{O}-\mathrm{N}$ glasses (Ln=La,Nd). Brit. Ceram. T. 1996, 95, 169-172.

29. Weldon, L.M.; Pomeroy, M.J.; Hampshire, S. Glasses in the rare-earth sialon system. Key Eng. Mat. 1996, 118, 241-248. [CrossRef]

30. Ohashi, M.; Nakamura, K.; Hirao, K.; Kanzaki, S.; Hampshire, S. Formation and Properties of Ln-Si-O-N Glasses (Ln=Lanthanides or Y). J. Am. Ceram. Soc. 1995, 78, 71-76. [CrossRef]

31. Makishima, A.; Mitomo, M.; Ii, N.; Tsutsumi, M. Microhardness and Transparency of an La-Si-O-N Oxynitride Glass. J. Am. Ceram. Soc. 1983, 66, C55-C56. [CrossRef]

32. Pasto, A.E. Causes and Effects of Fe-Bearing Inclusions in Sintered $\mathrm{Si}_{3} \mathrm{~N}_{4}$. J. Am. Ceram. Soc. 1984, 67, C178-C180. [CrossRef]

33. Ali, S.; Jonson, B. Glasses in the Ba-Si-O-N System. J. Am. Ceram. Soc. 2011, 94, 2912-2917. [CrossRef]

34. Wójcik, N.A.; Jonson, B.; Möncke, D.; Palles, D.; Kamitsos, E.I.; Ghassemali, E.; Seifedine, S.; Eriksson, M.; Ali, S. Influence of synthesis conditions on glass formation, structure and thermal properties in the Na2O-CaO-P2O5 system doped with Si3N4 and Mg. J. Non Cryst. Solids. 2018, 494, 66-77. [CrossRef]

35. Bulanova, M.V.; Zheltov, P.N.; Meleshevich, K.A.; Saltykov, P.A.; Effenberg, G.; Tedenac, J.C. Lanthanum-silicon system. J. Alloy. Compd. 2001, 329, 214-223. [CrossRef]

36. Greaves, G.N.; Fontaine, A.; Lagarde, P.; Raoux, D.; Gurman, S.J. Local structure of silicate glasses. Nature 1981, 293, 611-616. [CrossRef] 